\author{
Maria Śmiechowska \\ Uniwersytet Morski w Gdyni \\ e-mail: m.smiechowska@wpit.umg.edu.pl \\ ORCID: 0000-0001-6933-594X
}

\title{
CZYNNIKI WPLYWAJĄCE NA ATRAKCYJNOŚĆ KWIATÓW JADALNYCH
}

\section{FACTORS THAT INFLUENCE ATTRACTIVENESS OF EDIBLE FLOWERS}

DOI: $10.15611 /$ nit.2018.1.04

JEL Classification: Q19

Streszczenie: W ostatnich latach wzrosło zainteresowanie kwiatami, w tym szczególnie kwiatami jadalnymi. Pierwotnie kwiaty były wykorzystywane w celach ozdobnych. Takie ich przeznaczenie znajdujemy w starożytnych Chinach, Rzymie czy Egipcie. Wówczas służyły głównie jako ozdoba oraz źródło aromatów dla uczestników biesiad. Takie też funkcje kwiatów wykorzystywano w cesarskiej Francji. W późniejszym okresie francuscy perfumiarze zastosowali ekstrakty kwiatowe do produkcji zapachów zamkniętych w szklanych flakonach. Obecnie kwiaty jadalne traktowane są jako element dekoracji potraw i źródło wrażeń nie tylko estetycznych, ale także smakowych. Kwiaty jadalne są również źródłem substancji bioaktywnych, jak polifenole, witaminy, związki mineralne. Powstają ogrody kwiatów jadalnych celem popularyzowania i edukowania w zakresie bezpiecznej konsumpcji.

Słowa kluczowe: kwiaty jadalne, konsumpcja, zawartość substancji bioaktywnych, zapewnienie bezpieczeństwa, turystyka kulinarna.

Summary: In recent years, the interest in flowers has increased, in particular edible flowers. Originally flowers were used for ornamental purposes. We find such an application in ancient China, Rome or Egypt. At that time they served mainly as an ornament and source of aromas for participants of banquets. Such functions of flowers were also used in imperial France. Later, French perfumers applied flower extracts for the production of fragrances enclosed in glass bottles. Currently, edible flowers are treated as an element of food decoration and a source of sensations not only aesthetic but also tasteful. Edible flowers are also a source of bioactive substances like polyphenols, vitamins and minerals. Gardens of edible flowers are created to popularize and educate in the field of safe consumption.

Keywords: edible flowers, consumption, content of bioactive substances, ensuring safety, culinary tourism. 


\section{Wstęp}

Rośliny zielne składają się z części podziemnej i nadziemnej. Część podziemną stanowią kłącza lub korzenie, nadziemną zaś łodygi, liście, kwiaty i owoce. W tradycji zielarskiej od wieków wykorzystywano w fitoterapii rośliny zielne świeże i w postaci suszu, jednoskładnikowe i w formie mieszanek. Kompozycje ziół często zawierają kwiaty, jak np. kwiaty rumianku, nazywane koszyczkami, kwiatostany lipy, kwiaty malwy czy baldachogrona białego bzu. Analiza składu herbatek ziołowych wykazała, że zawierają one takie kwiaty, jak bratek, malwa, mlecz, bez czarny, hibiskus, rumianek i inne [Adamczak i in. 2015].

Świeże kwiaty od najdawniejszych czasów były używane przede wszystkim do dekorowania i aromatyzowania pomieszczeń. Do celów kulinarnych wykorzystywane są wszystkie części rośliny, w tym także kwiaty. W tradycji niektórych kultur kwiaty służyły i służą nadal do przygotowywania tak oryginalnych dań, jak zupa z kwiatów lotosu, czy przetworów, jak konfitura z płatków róż [Mukherjee i in. 2009; Kalemba-Drożdż 2017; Özcan 2002].

Ostatnio obserwujemy nowy trend polegający na szerokim wykorzystaniu przede wszystkim świeżych kwiatów do celów jadalnych. Niniejszy artykuł jest próbą przeglądu wiedzy o kwiatach jadalnych i próbą odpowiedzi na wiele pytań dotyczących konsumpcji kwiatów. Celem opracowania jest wskazanie kwiatów jadalnych wykorzystywanych do dekoracji potraw, szczególnie lodów, deserów i przystawek. Zainteresowanie kwiatami jadalnymi wykazuje też przemysł żywności funkcjonalnej i suplementów diety. Ogrody kwiatów jadalnych, jak niegdyś ogrody herbaciane i plantacje kawy, mogą się stać atrakcją kulinarną.

\section{Konsumpcja kwiatów jadalnych}

Wśród wielu roślin kwitnących są takie, których kwiaty są jadalne, i takie, których kwiaty nie nadają się do jedzenia. Głównym bowiem zadaniem roślin w naturze jest wydać owoce i nasiona, które przedłużą istnienie roślin i dlatego prawdopodobnie wiele kwiatów wytwarza substancje odstraszające czy wręcz trujące, aby uchronić się przed utratą kwiatów. Jednym z najważniejszych zadań jest wskazanie, które kwiaty mogą być przeznaczone do konsumpcji i czy ich konsumpcja jest bezpieczna. Zwykle nie zastanawiamy się, jaką część rośliny spożywamy. W kulinariach wykorzystujemy rośliny, opierając się najczęściej na przekazach historycznych i tradycji regionalnej. Rzadko uświadamiamy sobie, że kalafior i brokuł są kwiatostanami, że składnikiem przyprawy o nazwie zioła prowansalskie na terenie Niemiec jest kwiat lawendy. W Polsce od dawna wykorzystuje się kwiaty do celów leczniczych. Wchodzą one w skład różnych produktów farmaceutycznych, jak ekstrakty, nalewki, napary, odwary, krople, maści, mieszanki ziołowe i inne postaci.

Należy jednak udzielić odpowiedzi na pytanie, czy wszystkie kwiaty i kwiatostany lecznicze są jednocześnie jadalne? Z literatury przedmiotu wynika, że kwiaty 
arniki górskiej (Arnica montana L.), konwalii majowej (Convallaria majalis L.), podbiału (Tussilago farfara L.), wrotyczu (Tanacetum vulgare L.) czy zimowitu (Colchicum autumnale L.) wywierają bardzo silne działanie na organizm człowieka, a niektóre są wręcz trujące [Akinmoladun i in. 2014; Kristanc, Kreft 2016; Lahlou i in. 2008; Klintschar i in. 1999; Šutovská i in. 2014]. Otrzymywane z tych roślin zielnych i kwiatów substancje bioaktywne powinny być stosowane pod ścisłą kontrolą lekarską. Obecnie produkty otrzymywane z tych roślin są rzadko stosowane, ponieważ do lecznictwa wprowadzono wiele innych substancji leczniczych niewywierających działania toksycznego na ludzi i zwierzęta.

Zainteresowanie kwiatami jadalnymi to wynik poszukiwania nowych naturalnych produktów żywnościowych. Konsumenci coraz częściej wybierają produkty spożywcze zawierające naturalne składniki ze względu na obawy o niekorzystne skutki zdrowotne syntetycznych składników. Kwiaty jadalne można traktować jako świeżą żywność, która wnosi ciekawe elementy do kulinariów i zwyczajów żywieniowych (tab. 1).

Kwiaty mogą być wykorzystane w różnych formach i postaciach. O ile w celach leczniczych wykorzystuje się kwiaty i/lub części nadziemne roślin wraz z kwiatami najczęściej w stanie wysuszonym, o tyle do konsumpcji przeznacza się najczęściej kwiaty świeże lub częściowo poddane utrwaleniu, lecz forma utrwalenia nie powinna powodować ich zniszczenia. Kwiaty jadalne mogą też być daniem samodzielnym w postaci zupy, smażone w cieście naleśnikowym, jak pączki kwiatowe i kwiaty dyniowatych, zamrażane w lodach i deserach lodowych, czy wreszcie mogą stanowić składnik soku [Kalemba-Drożdż 2016].

Spośród kwiatów jadalnych szczególnie szeroko wykorzystywana jest róża - zarówno do bezpośredniego spożycia, jak i w przetwórstwie. Jest to kwiat, którego płatki od najdawniejszych czasów są przedmiotem zastosowań kulinarnych, kosmetycznych oraz w aromaterapii [Schmitzer i in. 2019].

\section{Postawy i zachowania konsumentów wobec kwiatów jadalnych}

Wymagania konsumentów w stosunku do żywności i żywienia rosną. Konsumenci koncentrują się zarówno na aspektach wizualnych, jak i na estetycznej wartości posiłków. Jednak badania dotyczące postaw i zachowań konsumentów w zakresie kwiatów jadalnych są nieliczne. Kwiaty, oprócz estetycznego wyglądu, odpowiadają również za specyficzny smak i zapach serwowanego jedzenia. Konsumenci postrzegają kwiaty poprzez atrakcyjny wygląd, wielkość, kształt, smak, zapach i kolorystykę.

Z badań Kelly i in. [2001] wynika, że konsumenci preferują kwiaty w kolorach żółtym, pomarańczowym i niebieskim. Benvenuti i in. [2016] przeprowadzili badania oceny sensorycznej kwiatów. Konsumenci oceniali takie cechy, jak pikantność, słodycz, zapach, miękkość, gorycz.

W tab. 1 podano nazwy kwiatów najczęściej stosowanych w żywieniu. 
Tabela 1. Kwiaty najczęściej wykorzystywane jako żywność

Table 1. Flowers most often used as foodstuffs

\begin{tabular}{|c|c|}
\hline Kwiat/Flower & Zastosowanie w żywieniu/Use in nutrition \\
\hline 1 & 2 \\
\hline $\begin{array}{l}\text { Kwiatostan bzu czarnego/ } \\
\text { Elderberry inflorescence }\end{array}$ & $\begin{array}{l}\text { Dekoracja dań i deserów, sałatki, sok / } \\
\text { Decoration of dishes and desserts, salads, juice }\end{array}$ \\
\hline $\begin{array}{l}\text { Kwiaty bratka / } \\
\text { Wild pansy flowers }\end{array}$ & $\begin{array}{l}\text { Dekoracja dań i deserów, sałatki / } \\
\text { Decoration of dishes and desserts, salads }\end{array}$ \\
\hline $\begin{array}{l}\text { Kwiaty i płatki chabra bławatka / } \\
\text { Cornflower flowers and petals }\end{array}$ & $\begin{array}{l}\text { Dekoracja dań i deserów / } \\
\text { Decoration of dishes and desserts }\end{array}$ \\
\hline $\begin{array}{l}\text { Kwiaty (płatki) chryzantemy / } \\
\text { Chrysanthemum flowers (petals) }\end{array}$ & $\begin{array}{l}\text { Dekoracja dań i deserów / } \\
\text { Decoration of dishes and desserts }\end{array}$ \\
\hline $\begin{array}{l}\text { Kwiaty (pączki kwiatowe) cukinii / } \\
\text { Zucchini flowers (flower buds) }\end{array}$ & $\begin{array}{l}\text { Dekoracja dań i deserów, naleśniki i czipsy / } \\
\text { Decoration of dishes and desserts, pancakes and crisps }\end{array}$ \\
\hline $\begin{array}{l}\text { Koszyczki kwiatowe i kwiaty cykorii / } \\
\text { Chicory inflorescence and flowers }\end{array}$ & $\begin{array}{l}\text { Dekoracja dań i deserów, sałatki / } \\
\text { Decoration of dishes and desserts, salads }\end{array}$ \\
\hline $\begin{array}{l}\text { Kwiaty (pączki kwiatowe) dyni / } \\
\text { Pumpkin flowers (flower buds) }\end{array}$ & $\begin{array}{l}\text { Dekoracja dań i deserów, naleśniki i czipsy / } \\
\text { Decoration of dishes and desserts, pancakes and crisps }\end{array}$ \\
\hline $\begin{array}{l}\text { Kwiaty fiołka / } \\
\text { Violet flowers }\end{array}$ & $\begin{array}{l}\text { Dekoracja dań i deserów, lodów i napojów / } \\
\text { Decoration of dishes and desserts, ice cream and drinks }\end{array}$ \\
\hline $\begin{array}{l}\text { Kwiaty floksów / } \\
\text { Phlox flowers }\end{array}$ & $\begin{array}{l}\text { Dekoracja dań i deserów, lodów i napojów / } \\
\text { Decoration of dishes and desserts, ice cream and drinks }\end{array}$ \\
\hline $\begin{array}{l}\text { Kwiaty forsycji / } \\
\text { Forsythia flowers }\end{array}$ & $\begin{array}{l}\text { Dekoracja dań i deserów, lodów i napojów / } \\
\text { Decoration of dishes and desserts, ice cream and drinks }\end{array}$ \\
\hline $\begin{array}{l}\text { Kwiaty frezji / } \\
\text { Freesia flowers }\end{array}$ & $\begin{array}{l}\text { Dekoracja dań, sałatki, napoje / } \\
\text { Decoration of dishes, salads, drinks }\end{array}$ \\
\hline $\begin{array}{l}\text { Kwiaty fuksji / } \\
\text { Fuchsia flowers }\end{array}$ & $\begin{array}{l}\text { Dekoracja dań i deserów, lodów i napojów / } \\
\text { Decoration of dishes and desserts, ice cream and drinks }\end{array}$ \\
\hline $\begin{array}{l}\text { Kwiaty głogu / } \\
\text { Hawthorn flowers }\end{array}$ & $\begin{array}{l}\text { Dekoracja deserów, lodów i napojów / } \\
\text { Decoration of desserts, ice cream and drinks }\end{array}$ \\
\hline $\begin{array}{l}\text { Kwiaty hibiskusa / } \\
\text { Hibiscus flowers }\end{array}$ & $\begin{array}{l}\text { Dekoracja dań i deserów, lodów i napojów / } \\
\text { Decoration of dishes and desserts, ice cream and drinks }\end{array}$ \\
\hline $\begin{array}{l}\text { Kwiaty jasnoty / } \\
\text { Dead-nettle flowers }\end{array}$ & $\begin{array}{l}\text { Dekoracja dań, deserów i napojów / } \\
\text { Decoration of dishes, desserts and drinks }\end{array}$ \\
\hline $\begin{array}{l}\text { Kwiaty jaśminu / } \\
\text { Jasmine flowers }\end{array}$ & $\begin{array}{l}\text { Dekoracja ciast, deserów, lodów i napojów / } \\
\text { Decoration of cakes, desserts, ice cream and drinks }\end{array}$ \\
\hline $\begin{array}{l}\text { Kwiaty (płatki) jeżówki / } \\
\text { Purple coneflower flowers (petals) }\end{array}$ & $\begin{array}{l}\text { Dekoracja dan / } \\
\text { Decoration of dishes }\end{array}$ \\
\hline $\begin{array}{l}\text { Kwiaty koniczyny / } \\
\text { Clover flowers }\end{array}$ & $\begin{array}{l}\text { Dekoracja dań, dodatek do ciast, sałatki / } \\
\text { Decoration of dishes, cake additive, salads }\end{array}$ \\
\hline $\begin{array}{l}\text { Kwiaty lawendy / } \\
\text { Lavender flowers }\end{array}$ & $\begin{array}{l}\text { Dekoracja dań i deserów, lodów i napojów / } \\
\text { Decoration of dishes and desserts, ice cream and drinks }\end{array}$ \\
\hline $\begin{array}{l}\text { Kwiaty (płatki) maku polnego / } \\
\text { Common poppy flowers (petals) }\end{array}$ & $\begin{array}{l}\text { Dekoracja dań i deserów, lodów i napojów / } \\
\text { Decoration of dishes and desserts, ice cream and drinks }\end{array}$ \\
\hline
\end{tabular}


Tabela 1, cd.

\begin{tabular}{|c|c|}
\hline 1 & 2 \\
\hline $\begin{array}{l}\text { Kwiaty (płatki) malwy / } \\
\text { Hollyhocks flowers (petals) }\end{array}$ & $\begin{array}{l}\text { Dekoracja dań i deserów / } \\
\text { Decoration of dishes and desserts }\end{array}$ \\
\hline $\begin{array}{l}\text { Kwiaty (płatki) nagietka / } \\
\text { Marigold flowers (petals) }\end{array}$ & $\begin{array}{l}\text { Dekoracja dań i deserów, sałatki, sok / } \\
\text { Decoration of dishes and desserts, salads, juice }\end{array}$ \\
\hline $\begin{array}{l}\text { Kwiaty nasturcji / } \\
\text { Nasturtium flowers }\end{array}$ & $\begin{array}{l}\text { Dekoracja dań, sałatki / } \\
\text { Decoration of dishes, salads }\end{array}$ \\
\hline $\begin{array}{l}\text { Kwiaty niecierpka / } \\
\text { Impatiens flowers }\end{array}$ & $\begin{array}{l}\text { Dekoracja dań i deserów, sałatki / } \\
\text { Decoration of dishes and desserts, salads }\end{array}$ \\
\hline $\begin{array}{l}\text { Kwiaty niezapominajki / } \\
\text { Forget-me-not flowers }\end{array}$ & $\begin{array}{l}\text { Dekoracja dań, sałatki / } \\
\text { Decoration of dishes, salads }\end{array}$ \\
\hline $\begin{array}{l}\text { Kwiaty ogórecznika / } \\
\text { Starflower flowers }\end{array}$ & $\begin{array}{l}\text { Dekoracja dań, sałatki / } \\
\text { Decoration of dishes, salads }\end{array}$ \\
\hline $\begin{array}{l}\text { Kwiaty petunii ogrodowej / } \\
\text { Petunia flowers }\end{array}$ & $\begin{array}{l}\text { Dekoracja dań, sałatki / } \\
\text { Decoration of dishes, salads }\end{array}$ \\
\hline $\begin{array}{l}\text { Kwiaty pierwiosnka / } \\
\text { Primula flowers }\end{array}$ & $\begin{array}{l}\text { Dekoracja dań i deserów, sałatki / } \\
\text { Decoration of dishes and desserts, salads }\end{array}$ \\
\hline $\begin{array}{l}\text { Kwiaty piwonii / } \\
\text { Peony flowers }\end{array}$ & $\begin{array}{l}\text { Dekoracja dań i deserów, napoje / } \\
\text { Decoration of dishes and desserts, drinks }\end{array}$ \\
\hline $\begin{array}{l}\text { Kwiaty (płatki) róży / } \\
\text { Rose flowers (petals) }\end{array}$ & $\begin{array}{l}\text { Dekoracja dań i deserów, lody, napoje, soki / } \\
\text { Decoration of dishes and desserts, ice cream, drinks, juices }\end{array}$ \\
\hline $\begin{array}{l}\text { Kwiaty rumianku / } \\
\text { Mayweed flowers }\end{array}$ & $\begin{array}{l}\text { Dekoracja dań, deserów, napoje / } \\
\text { Decoration of dishes and desserts, drinks }\end{array}$ \\
\hline $\begin{array}{l}\text { Kwiaty (płatki) słonecznika / } \\
\text { Sunflower flowers (petals) }\end{array}$ & $\begin{array}{l}\text { Dekoracja dań, sałatki / } \\
\text { Decoration of dishes, salads }\end{array}$ \\
\hline $\begin{array}{l}\text { Kwiaty stokrotki / } \\
\text { Daisy flowers }\end{array}$ & $\begin{array}{l}\text { Dekoracja dań, sałatki, napoje / } \\
\text { Decoration of dishes, salads, drinks }\end{array}$ \\
\hline $\begin{array}{l}\text { Kwiaty storczyka / } \\
\text { Orchid flowers }\end{array}$ & $\begin{array}{l}\text { Dekoracja dań, desery, sałatki / } \\
\text { Decoration of dishes, desserts, salads }\end{array}$ \\
\hline $\begin{array}{l}\text { Kwiaty truskawki i poziomki / } \\
\text { Strawberry and wild strawberry flowers }\end{array}$ & $\begin{array}{l}\text { Dekoracja dań, deserów, lodów / } \\
\text { Decoration of dishes, desserts, ice creams }\end{array}$ \\
\hline $\begin{array}{l}\text { Kwiaty (płatki) wiesiołka / } \\
\text { Evening primrose flowers }\end{array}$ & $\begin{array}{l}\text { Dekoracja dań i deserów, sałatki, napoje / } \\
\text { Decoration of dishes and desserts, salads, drinks }\end{array}$ \\
\hline $\begin{array}{l}\text { Kwiaty wiśni i czereśni / } \\
\text { Cherry and sweet cherry flowers }\end{array}$ & $\begin{array}{l}\text { Dekoracja dań, deserów, lodów / } \\
\text { Decoration of dishes, desserts, ice creams }\end{array}$ \\
\hline $\begin{array}{l}\text { Kwiatostany i kwiaty wrzosu / } \\
\text { Heather inflorescence and flowers }\end{array}$ & $\begin{array}{l}\text { Dekoracja dań i deserów, napoje / } \\
\text { Decoration of dishes and desserts, salads, drinks }\end{array}$ \\
\hline $\begin{array}{l}\text { Kwiaty żarnowca / } \\
\text { Common broom flowers }\end{array}$ & $\begin{array}{l}\text { Dekoracja potraw / } \\
\text { Decoration of dishes }\end{array}$ \\
\hline
\end{tabular}

Źródło: opracowanie własne na podstawie: [Kalemba-Drożdż 2016; Kalemba-Drożdż 2017; Mlcek, Rop 2011; Benvenuti i in. 2016].

Source: own elaboration based on: [Kalemba-Drożdż 2016; Kalemba-Drożdż 2017; Mlcek, Rop 2011; Benvenuti i in. 2016]. 


\section{Kwiaty jadalne jako źródło substancji bioaktywnych}

Wprowadzenie do spożycia kwiatów wywołało pytania o wartości kwiatów jadalnych. Czy oprócz tego, że dodają świeżego i egzotycznego aromatu, delikatnego smaku i atrakcyjnego wyglądu, dzięki czemu są coraz częściej stosowane w kuchni, zapewniają także korzyści zdrowotne dla konsumenta? Odpowiedzią na to pytanie są wyniki badań dotyczące składu substancji aktywnych izolowanych z kwiatów jadalnych. Badania te ukazały bogactwo związków bioaktywnych zawartych w kwiatach. Do najczęściej badanych związków należą polifenole i ich antyoksydacyjne właściwości [Chen i in. 2015; Pinela i in. 2017; Pires i in. 2018]. W kwiatach jadalnych wykrywano również karotenoidy, antocyjany, witaminy A, C, E oraz wiele związków mineralnych. Nowe dane dotyczące jakości odżywczej kwiatów są również bardzo ważną przyczyną rosnącego zainteresowania ich spożyciem [Mlcek, Rop 2011].

\section{Bezpieczeństwo konsumpcji kwiatów jadalnych}

O ile dla innych produktów pochodzenia roślinnego, takich jak warzywa, owoce czy zioła i przyprawy, określono wymagania i przepisy dotyczące zapewnienia bezpieczeństwa, o tyle dla kwiatów jadalnych takich przepisów i kryteriów bezpieczeństwa brakuje. Niemniej jednak zagrożenia przenoszone przez jadalne kwiaty zostały już zgłoszone w systemie szybkiego ostrzegania o żywności i paszach (RASFF) (tab. 2).

Tabela 2. Zanieczyszczenia stwierdzone w kwiatach jadalnych zgłoszone w systemie szybkiego ostrzegania o żywności i paszach (RASFF)

Table 2. Food contaminants identified in edible flowers reported in Rapid Alert System for Food and Feed (RASFF)

\begin{tabular}{|l|l|l|c|}
\hline \multicolumn{1}{|c|}{ Kwiat/Flower } & \multicolumn{1}{|c|}{$\begin{array}{c}\text { Kraj/ } \\
\text { Country }\end{array}$} & \multicolumn{1}{|c|}{$\begin{array}{c}\text { Identyfikowany problem/ } \\
\text { Identified problem }\end{array}$} & Rok/Year \\
\hline Lipa srebrzysta/Silver lime & Albania & $\begin{array}{l}\text { Dimetoat - insektycyd/ } \\
\text { Dimetoat - insecticide } \\
\text { Zaatakowany przez owady i pleśnie, } \\
\text { odchody gryzoni/Attacked by insects } \\
\text { and moulds, rodent feces } \\
\text { Siarczyny - niedeklarowana obecność/ }\end{array}$ & 2008 \\
Cynamon/Cinnamon & Sri Lanka & $\begin{array}{l}\text { Sulfites - nondeclared presence } \\
\text { Salmonella Mbandaka }\end{array}$ & 2005 \\
$\begin{array}{l}\text { Ślieże kwiaty jadalne/Fresh } \\
\text { edible flowers } \\
\text { Suszone kwiaty nagietka/Dried } \\
\text { marigold flowers }\end{array}$ & $\begin{array}{l}\text { Tajlandia/ } \\
\text { Thailand } \\
\text { Egipt/Egypt }\end{array}$ & Salmonella Hadar & 2004 \\
\hline
\end{tabular}

Źródło/Source: [Fernandes i in. 2017]. 
$\mathrm{Z}$ danych zawartych w tab. 2 wynika zatem, że najważniejszym zadaniem jest zapewnienie bezpieczeństwa kwiatom przeznaczonym do celów jadalnych. Zasady uprawy kwiatów jadalnych muszą być zupełnie inne aniżeli kwiatów przeznaczonych do celów dekoracyjnych lub bukieciarstwa. Sprawę utrudnia brak uregulowań prawnych w zakresie wymagań stawianych uprawom, a także warunków przechowywania i konsumpcji. W wypadku warzyw i owoców istnieją przepisy i wymagania dotyczące określenia dopuszczalnego poziomu zanieczyszczeń, natomiast w odniesieniu do kwiatów jadalnych brakuje takich uregulowań.

Według niektórych autorów wiele kwiatów można uznać za tzw. nową żywność, ponieważ nie stanowiły one produktu żywnościowego przed dniem 15 maja 1997 r., zanim weszło w życie Rozporządzenie (WE) 258/97 w sprawie nowej żywności i nowych składników żywności [Egebjerg i in. 2018]. Spożywanie kwiatów jadalnych można również uważać za żywność tradycyjna, która musi mieć udokumentowaną historię konsumpcji. Historia bezpiecznego stosowania żywności dotyczy co najmniej 25 lat w ramach zwyczajowej diety znacznej liczby osób. Najnowsze Rozporządzenie (UE) 2015/2283 weszło w życie 1 stycznia 2018 r., a jedną z podstawowych jego zasad jest to, że nowa żywność musi być bezpieczna dla konsumentów. Jest to niezwykle istotne w kontekście zagrożeń identyfikowanych w kwiatach jadalnych.

\section{Podsumowanie}

Kwiaty jadalne zyskują coraz większą popularność i są akceptowane przez konsumentów, kucharzy i cukierników. Wpływają na konsumenta przede wszystkim poprzez walory sensoryczne, jak smak i aromat. Wywołują pozytywne wrażenia estetyczne. Kwiaty jadalne dostarczają także związków bioaktywnych w postaci polifenoli, witamin i związków mineralnych. Każdy produkt spożywczy musi być przede wszystkim bezpieczny dla konsumenta, a w wypadku kwiatów jadalnych brakuje jednoznacznych uregulowań prawnych co do takich elementów, jak wykaz kwiatów dozwolonych do spożycia, warunki uprawy, terminy zbioru, warunki przechowywania i substancje niedozwolone do stosowania w ochronie kwiatów jadalnych. W tej sytuacji najbezpieczniejszym systemem jest uprawa ekologiczna lub zbiór ze stanu naturalnego, podobnie jak w wypadku pozyskiwania ziół.

W celu popularyzacji kwiatów jadalnych tworzone są ogrody kwiatowe i urządzane są festiwale kwiatów jadalnych. W Polsce Kulinarny Festiwal Kwiatów Jadalnych jest organizowany w Ogrodach Hortulus w Dobrzycy k/Koszalina. III Festiwal Kwiatów Jadalnych odbył się 14-15 lipca 2018 roku.

\section{Literatura}

Adamczak A., Forycka A., Buchwald W., 2015, Skład herbatek owocowych dostępnych na polskim rynku artykutów spożywczych, Postępy Fitoterapii, 4, s. 216-222. 
Akinmoladun A.C., Olaleye M.T., Farombi E.O., 2014, Cardiotoxicity and Cardioprotective Effects of African Medicinal Plants, [w:] Kuete V. (red.), Toxicological Survey of African Medicinal Plants, Elsevier Inc., https://www.sciencedirect.com/book/9780128000182/toxicological-survey-of-african-medicinal-plants (25.08.2018).

Benvenuti S., Bortolotti E., Maggini R., 2016, Antioxidant power, anthocyanin content and organoleptic performance of edible flowers, Scientia Horticulturae, 199, s. 170-177.

Chen G.-L., Chen S.-G., Xie Y.-Q., Chen F., Zhao Y.-Y., Luo Ch.-X., Gao Y.-Q., 2015, Total phenolic, flavonoid and antioxidant activity of 23 edible flowers subjected to in vitro digestion, Journal of Functional Foods, 17, s. 243-259.

Egebjerg M.M, Olesen P.T., Eriksen F.D., Ravn-Haren G., Bredsdorff L., Pilegaard K., 2018, Are wild and cultivated flowers served in restaurants or sold by local producers in Denmark safe for the consumer?, Food and Chemical Toxicology, 120, s. 129-142.

Fernandes L., Casalb S., Pereira J.A., Saraivac J.A., Ramalhosa E., 2017, Edible flowers: A review of the nutritional, antioxidant, antimicrobial properties and effects on human health, Journal of Food Composition and Analysis, 60, s. 38-50.

Kalemba-Drożdż M., 2016, Kwiaty jadalne, Pascal, Bielsko-Biała.

Kalemba-Drożdż M., 2017, Różane przepisy, Pascal, Bielsko-Biała.

Kelly K.M., Behe B.K., Biernbaum J.A., Poff K.L., 2001, Consumer preference for edible flower color, container size, and price, Hort Science, 36(4), s. 801-804.

Klintschar M., Beham-Schmidt C., Radner H., Henning G., Roll P., 1999, Colchicine poisoning by accidental ingestion of meadow saffron (Colchicum autumnale): Pathological and medicolegal aspects, Forensic Science International, 106, s. 191-200.

Kristanc L., Kreft S., 2016, European medicinal and edible plants associated with subacute and chronic toxicity, part I: Plants with carcinogenic, teratogenic and endocrine-disrupting effects, Food and Chemical Toxicology, 92, s. 150-164.

Lahlou S., Zafar H. Israili Z.H., Lyoussi B., 2008, Acute and chronic toxicity of a lyophilised aqueous extract of Tanacetum vulgare leaves in rodents, Journal of Ethnopharmacology, 117, s. 221-227.

Mlcek J., Rop O., 2011, Fresh edible flowers of ornamental plants - a new source of nutraceutical foods, Trends in Food Science \& Technology, 22, s. 561-569.

Mukherjee P.K., Mukherjee D., Amal K. Maji A.K., Rai S., Heinrich M., 2009, The sacred lotus (Nelumbo nucifera) - phytochemical and therapeutic profile, Journal of Pharmacy and Pharmacology, 61, s. 407-422.

Özcan M., 2002, Nutrient composition of rose (Rosa canina) seed and oils, Journal Medicinal Food, 5(3), s. 137-140.

Pinela J., Carvalho A.M., Ferreira I.C.F.R., 2017, Wild edible plants: Nutritional and toxicological characteristics, retrieval strategies and importance for today's society, Food and Chemical Toxicology, 110, s. 165-188.

Pires C.S.P.T., Dias M.I., Barros L., Ricardo C., Calhelha R.C., Alves M.J., Oliveira M.B.P.P., Santos-Belga C., Ferreira I.C.F.R., 2018, Edible flowers as sources of phenolic compounds with bioactive potential, Food Research International, 105, s. 580-588.

Rozporządzenie Parlamentu Europejskiego i Rady (UE) 2015/2283 z dnia 25 listopada 2015 r. w sprawie nowej żywności, zmieniające rozporządzenie Parlamentu Europejskiego i Rady (UE) nr 1169/2011 oraz uchylające rozporządzenie (WE) nr 258/97 Parlamentu Europejskiego i Rady oraz rozporządzenie Komisji (WE) nr 1852/2001.

Schmitzer V., Mikulic-Petkovsek M., Stampar F., 2019, Traditional rose liqueur - A pink delight rich in phenolics, Food Chemistry, 272, s. 434-440.

Sutovská M., Capek P., Kočmalová M., Pawlaczyk I., Zaczyńska E., Czarny A., Uhliariková I., Gancarz R., Fraňová S., 2014, Characterization and pharmacodynamic properties of Arnica montana complex, International Journal of Biological Macromolecules, 69, s. 214-221. 